\title{
A dendritic cell targeted vaccine induces long-term HIV-specific immunity within the gastrointestinal tract
}

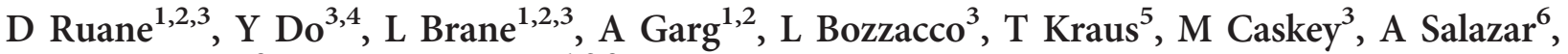 \\ C Trumpheller ${ }^{3}$ and S Mehandru ${ }^{1,2,3}$
}

Despite significant therapeutic advances for HIV-1 infected individuals, a preventative HIV-1 vaccine remains elusive. Studies focusing on early transmission events, including the observation that there is a profound loss of gastrointestinal (GI) $\mathrm{CD}^{+}$Tcells during acute HIV-1 infection, highlight the importance of inducing HIV-specific immunity within the gut. Here we report on the generation of cellular and humoral immune responses in the intestines by a mucosally administered, dendritic cell (DC) targeted vaccine. Our results show that nasally delivered $\alpha$-CD205-p24 vaccine in combination with polyICLC, induced polyfunctional immune responses within naso-pulmonary lymphoid sites that disseminated widely to systemic and mucosal (GI tract and the vaginal epithelium) sites. Qualitatively, while $\alpha$-CD205p24 prime-boost immunization generated $\mathrm{CD} 4^{+}$T-cell responses, heterologous prime-boost immunization with $\alpha-$ CD205-p24 and NYVAC gag-p24 generated high levels of HIV-specific CD4 ${ }^{+}$and CD8 ${ }^{+}$Tcells within the GI tract. Finally, DC-targeting enhanced the amplitude and longevity of vaccine-induced immune responses in the GI tract. This is the first report of a nasally delivered, DC-targeted vaccine to generate HIV-specific immune responses in the GI tract and will potentially inform the design of preventative approaches against HIV-1 and other mucosal infections.

\section{INTRODUCTION}

Despite a marked improvement in survival of HIV-1 infected patients with combination antiretroviral therapy, HIV vaccine development remains a global priority. A key feature of HIV-1 transmission includes the preferential targeting of virus to gastrointestinal (GI) lymphocytes during acute HIV-1 (refs $1,2)$ and $\mathrm{SIV}^{3}$ infections, independent of the route of viral inoculation. A recent study demonstrated a strikingly rapid seeding of viral reservoirs, including those in the GI tract, even before the appearance of systemic viremia in SIV-infected rhesus macaques. ${ }^{4}$ Therefore, it has been argued that the goal of an effective HIV vaccine should be to interrupt mucosal transmission at its earliest stages and to prevent viral production in mucosal tissues. ${ }^{5}$

Targeting antigens to dendritic cells (DC) is a strategy to enhance the effectiveness of vaccination, reviewed in ref. 6 .
Among the DC-associated receptors that have been targeted to boost cellular and humoral adaptive immunity are $\mathrm{Fc} \gamma$ receptors, ${ }^{7}$ MHC II molecules, ${ }^{8} \mathrm{CD} 40$ (ref. 9), CD11b (ref. 10), $\mathrm{CD} 11 \mathrm{c}^{11}$ and a number of $\mathrm{C}$ type lectins including $\mathrm{CD} 205^{12}$, $\mathrm{CD} 207,{ }^{13}$ macrophage mannose receptor, ${ }^{14}$ CLEC9A, ${ }^{15}$ DCIR2, ${ }^{16}$ DC-SIGN, ${ }^{17}$ and dectin 1 (ref. 18). CD205 or DEC-205 targeting is perhaps best studied in the context of HIV-1 vaccine design. This involves engineering an $\alpha$-CD205p24 fusion construct that is then administered in combination with an adjuvant such as polyICLC to boost HIV-1-specific immune responses in mice, ${ }^{19}$ non human primates, ${ }^{20}$ and humans. ${ }^{21}$ In the present study, we have used an analog of polyriboinosinic-polyribocytoidylic acid (Poly IC) as the adjuvant. PolyIC is a synthetic double-stranded RNA, recognized by TLR-3 and other intracellular receptors. A complex of

${ }^{1}$ Division of Gastroenterology, Department of Medicine, Icahn School of Medicine at Mount Sinai, New York, New York, USA. ${ }^{2}$ The Immunology Institute, Icahn School of Medicine at Mount Sinai, New York, New York, USA. ' Laboratory of Cellular Physiology and Immunology, Rockefeller University, New York, New York, USA. ${ }^{4}$ School of NanoBioscience and Chemical Engineering, Ulsan National Institute of Science and Technology, Ulsan, Republic of Korea. ${ }^{5}$ Division of Obstetrics, Gynecology and Reproductive Science Icahn School of Medicine at Mount Sinai, New York, New York, USA and ${ }^{6}$ Oncovir, Washington, District of Columbia, USA. Correspondence: S Mehandru (Saurabh.mehandru@mssm.edu) 
poly IC with poly-L-lysine and carboxymethylcellulose (poly ICLC), is five to ten times more resistant to hydrolysis by RNAse than the parent poly I:C. In addition, PolyICLC demonstrates a greater potency for interferon induction than its parent, PolyIC. ${ }^{22}$ Notably, GI mucosal immunity, highly relevant to HIV-1 vaccine development effort, has never been examined using a DC-targeted vaccine.

Our goal here was to induce and detect HIV-1-specific $\mathrm{T}$ - and B-cell responses in the GI tract. We focused on mucosal vaccination as it offers many attractive features including the ease of administration, potential for mass immunization, reduced cost of production, storage and delivery. In addition, mucosal vaccination is considered superior to systemic vaccination for recruiting cells to local, ${ }^{23}$ regional, ${ }^{24,25}$ and distant mucosal sites ${ }^{26}$ for non-HIV and HIV- (and SIV-) specific $^{27,28}$ antigens. In studying the mechanism(s) of protection elicited by mucosal vaccines, we have previously demonstrated that intranasal vaccination licenses $\mathrm{T}$ cells $^{29}$ and B cells to the GI tract through the induction of gut homing receptors $\alpha 4 \beta 7$ and CCR9. In the present study, we demonstrate that intranasal delivery of an $\alpha$-CD205-p24 fusion antibody induces and directs HIV-specific T and B cells to the GI tract. Thus, here we define the first study of a DC-targeted vaccine to induce GI immune responses directed against HIV. The data presented herein is of relevance to the HIV-1 vaccine development effort, as well as for mucosal vaccination against other enteric and pulmonary pathogens.

\section{RESULTS}

Intranasal immunization with $\alpha$-CD205-p24 and poly ICLC induces HIV-specific CD4 ${ }^{+}$T-cell responses in the intestinal lamina propria

With the goal of inducing HIV-specific immune responses in the GI tract, we compared mucosal and systemic routes of vaccine delivery. $\mathrm{C} 57 \mathrm{Bl} / 6$ mice were immunized with $5 \mu \mathrm{g}$ of $\alpha$-CD205-p24 and $50 \mu \mathrm{g}$ of polyICLC, administered either intranasally (IN), intraperitoneally (IP), intravenously (IV), subcutaneously (SC), or via the intramuscular (IM) routes. A booster dose of the vaccine was administered 4 weeks after priming. As a control, $\alpha$-CD205-empty, which did not carry any antigen, and polyICLC were administered IP (Ctrl). One-week post boost, mononuclear cells were isolated from the intestinal lamina propria and spleen (Figure 1a).

Interferon- $\gamma$ (IFN- $\gamma$ ) producing $\mathrm{CD}^{+} \mathrm{T}$ cells were detected in the small intestinal lamina propria (SILP) following IN and IP routes of vaccine delivery. In contrast, IV, SC, and IM vaccination failed to induce detectable levels of antigen-specific $\mathrm{CD} 4{ }^{+} \mathrm{T}$ cells in the SILP (Figure $\mathbf{1 b}$ and $\mathbf{c}$ ). Similar findings were noted in the spleen (Figure 1d). Furthermore, IN and IP immunization induced HIV p24-specific IgA $^{+}$B cells in the SILP, as confirmed by ELISPOT (Figure 1e). As IN immunization is clinically feasible, it was explored further and was found to induce p24-specific IgA and IgG antibodies in the serum (Figure 1f and $\mathbf{g}$ ).
Intranasal immunization induces IFN- $\gamma^{+} \mathrm{CD} 4^{+} \mathrm{T}$ cells locally, followed by dissemination to the effector sites of the Gl tract

To examine the sites of induction of immunity following IN vaccination, we isolated mononuclear cells from the nose, mediastinal LN (Med LN) and lungs of vaccinated mice. HIV-p24-specific $\mathrm{CD}^{+}{ }^{+} \mathrm{T}$ cells were readily detectable in lungs, Med LN, and nose suggesting a local generation of vaccine-induced immune response (Figure $\mathbf{2} \mathbf{a}$ and $\mathbf{b}$ ). In fact, striking frequencies of HIV-specific $\mathrm{T}$ cells were detected in the lung, highlighting the potential efficacy of IN delivered DC-targeted vaccines against other pulmonary pathogens like pneumonic plague. ${ }^{30}$

We hypothesized that GI immune responses were being induced due to the dissemination of antigen-specific cells from local sites of induction as opposed to generation of GI immune responses due to swallowed antigen. Accordingly, we examined the inductive (Peyer's Patches-PP and mesenteric LN-MLN) and effector (SILP and colonic lamina propria (CLP)) sites of the GI tract separately. While HIV-p24-specific IFN- $\gamma^{+} \mathrm{CD} 4{ }^{+}$ $T$ cells were detected in the SILP and CLP, the PP and MLN of immunized animals did not contain appreciable levels of antigen-specific $\mathrm{CD} 4{ }^{+} \mathrm{T}$ cells (Figure $2 \mathrm{c}$ and $\mathbf{d}$ ). These data demonstrated that the immune response following IN vaccination was predominantly noted in the GI effector sites as opposed to the inductive sites. Finally, in addition to the GI tract, we examined the systemic compartments and female reproductive tract and found that IN immunization induces HIV-specific $\mathrm{CD} 4{ }^{+} \mathrm{T}$ cells in the spleen and genital tract in addition to the GI tract (Figure $2 \mathbf{e}$ and $\mathbf{f}$ ).

Combined, these data demonstrate that following IN immunization, antigen-specific $\mathrm{T}$ cells are induced locally within the upper and lower respiratory tracts and disseminate to systemic sites, as well as to the gastrointestinal and genital mucosae.

\section{Classical dendritic cells mediated the induction of IFN- $\gamma \mathrm{CD}^{+} \boldsymbol{T}$ cells following intranasal vaccination}

To assess the role of classical dendritic cells (cDC) in our IN immunization experiments, $z b t b 46^{D T R}$ mice were used. In these mice, a zinc finger transcription factor, $Z b t b 46$, which is specific to $\mathrm{cDCs}$, is conditionally deleted, thus, distinguishing $\mathrm{CDCs}$ from other cells types expressing CD11c. ${ }^{31}$

Chimerization to WT mice was needed to avoid toxicity associated with multiple administrations of diphtheria toxin. Zbtb46 ${ }^{\text {DTR }}$ chimera and $\mathrm{C} 57 \mathrm{Bl} / 6 \mathrm{WT}$ chimeric mice received $0.5 \mu \mathrm{g}$ of DT IP on day -2 before vaccination (Figure 3a). Depletion of the cDCs was confirmed in the lungs and spleen of representative mice (data not shown). Both groups of mice were then immunized with $\alpha$-CD205-p24 (5 $\mu \mathrm{g})$ and polyICLC $(50 \mu \mathrm{g})$ in a prime-boost regimen as described. To maintain the deletion of cDCs during the course of immunization, $0.5 \mu \mathrm{g}$ of DT was administered IP every 5 days over the priming period and another dose of $0.5 \mu \mathrm{g}$ of DT was administered IP on day 28 and 4 days following the booster vaccination (Figure 3a). IFN- $\gamma^{+}$T effector responses were strikingly impaired in all of 
a

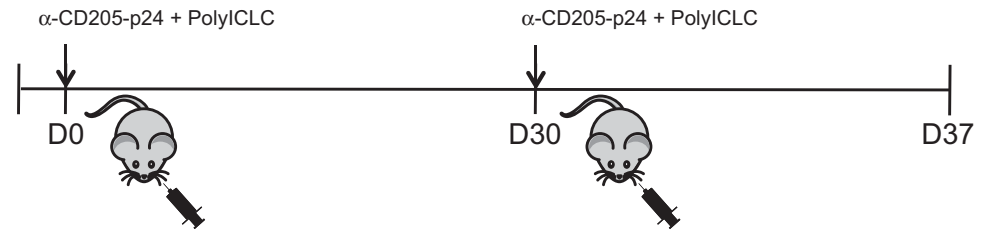

b

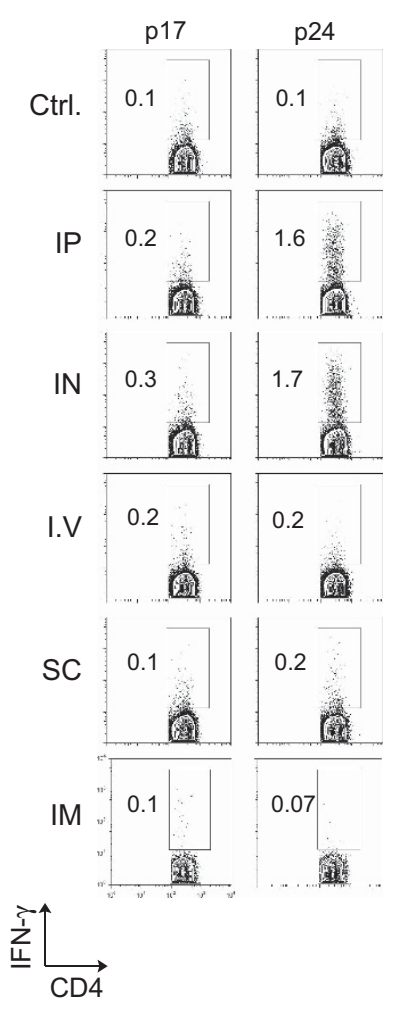

C

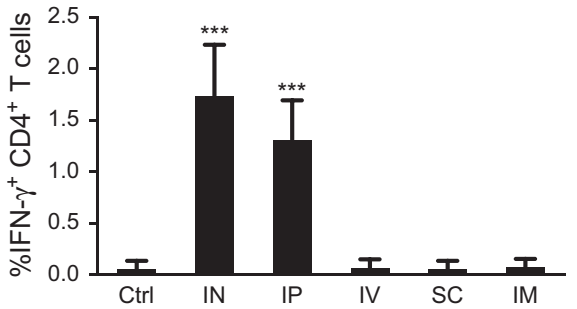

d

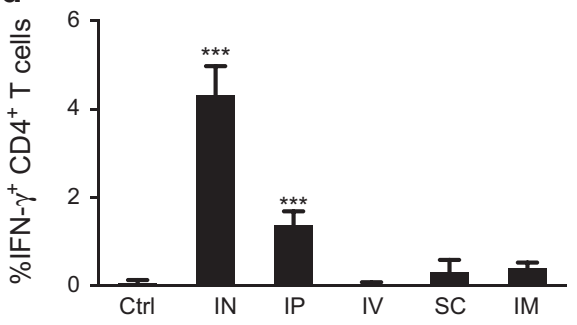

e

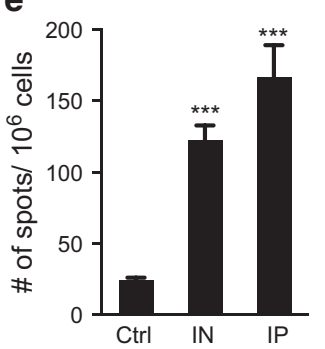

f

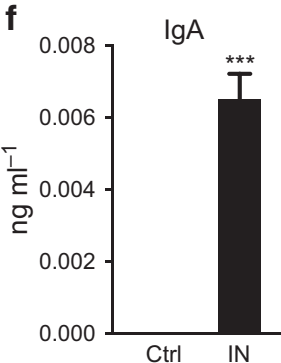

g

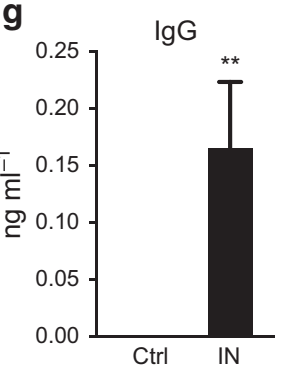

Figure 1 Intranasal immunization with $\alpha$-CD205-p24 and poly ICLC delivered IN and IP elicit antigen-specific IFN- $\gamma^{+}$CD4 ${ }^{+}$T-cell responses in the gastrointestinal (GI) lamina propria. C57BI/6 mice were immunized with $\alpha$-CD205-p24 fusion mAb (5 $\mu \mathrm{g})$ and poly ICLC (50 $\mu \mathrm{g})$. The vaccine was delivered IP, IN, IV, Sc or IM in a prime-boost manner. $\alpha$-CD205-empty mAb $(5 \mu \mathrm{g})$ delivered IP served as control. Mononuclear cells were isolated from the small intestinal lamina propria (SILP) and spleen 1 week post-vaccine boost. IFN- $\gamma$ secretion in response to HIV p24 (immunizing) or p17 (control) peptide pools was evaluated by intracellular cytokine staining. (a) Shows the schema of immunization. (b) FACS plots from a representative experiment.

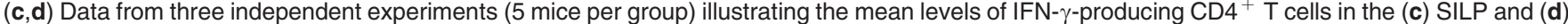
Spleen. Background (p17) subtracted p24 data are shown. Statistical comparisons to $\alpha$-CD205-empty (Ctrl) mice are shown. (e) ELISPOT quantification of p24-specific lgA ${ }^{+}$cells in the GI tract following IN and IP immunization. $\alpha$-CD205-empty mAb $(5 \mu \mathrm{g})$ delivered IP served as control. Mean data from two experiments, 5 mice per group. Statistical comparisons to $\alpha$-CD205-empty (Ctrl) mice are shown. (f, $\mathbf{g})$ ELISA quantification of p24-specific (f) IgA and (g) $\operatorname{IgG}$ in the serum from the above experiments. Error bars show mean \pm s.d. ${ }^{* *}=P<0.001$. ELISA, enzyme-linked immunosorbent assay; ELISPOT, enzyme-linked immunospot assay; FACS, fluorescence activated cell sorting; IN, intranasally; IP, intraperitoneally; IV, intravenously; poly ICLC, poly-L-lysine and carboxymethylcellulose.

the compartments examined (lung, spleen, and GI tract) in $Z b t b 46^{D T R}$ but not WT mice (Figure $3 \mathbf{b}$ and $\mathbf{c}$ ) demonstrating that cDCs mediate the effect of IN vaccination.

\section{$\alpha-C D 205-p 24$ immunization enhances gastrointestinal $\mathrm{CD}^{+}{ }^{+} \mathrm{T}$-cell responses relative to untargeted protein immunization}

Having shown that IN immunization mediated intestinal responses were DC mediated, we wanted to compare the efficacy of DC-targeted vaccination with untargeted protein vaccination. $\mathrm{C} 57 \mathrm{Bl} / 6$ mice were immunized $\mathrm{IN}$ with $0.5,5$ and $15 \mu \mathrm{g}$ of p24 protein plus polyICLC and compared with $0.5,5$, and $15 \mu \mathrm{g}$ of IN delivered $\alpha$-CD205-p24 and poly ICLC. The DC-targeted approach was more potent at inducing antigenspecific immunity within the GI tract compared with untargeted protein vaccination as significantly higher levels of HIV p24 specific, IFN $-\gamma^{+} \mathrm{CD} 4{ }^{+}$T cells were observed in the lungs, SILP, and CLP in the DEC-205-targeted vaccine group compared with untargeted p24 immunized group (Figure 4a-c).

Intranasal immunization with $\alpha$-CD205-p24-induced antigen-specific Th1 and Th17 responses in the Gl tract Having established that IN vaccination induces antigen specific T cells in the GI effector compartments, the poly-functionality 
a

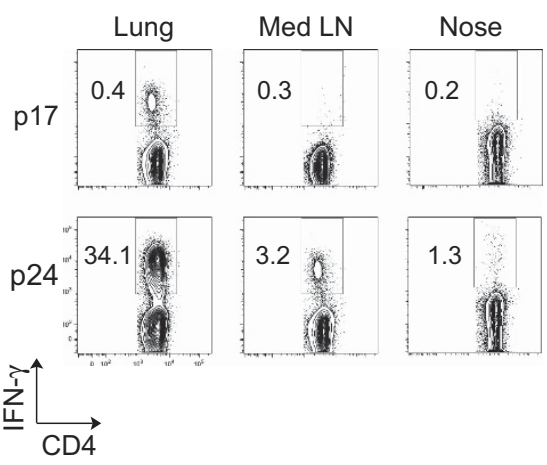

C

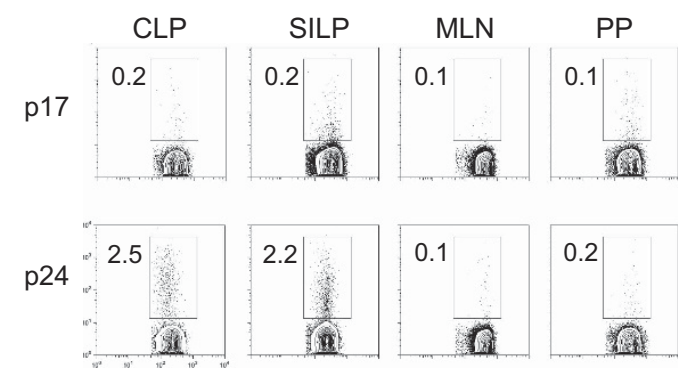

$\stackrel{\overrightarrow{\underline{Z}}}{\stackrel{\overrightarrow{1}}{\longrightarrow}} \underset{\mathrm{CD} 4}{\longrightarrow}$

e
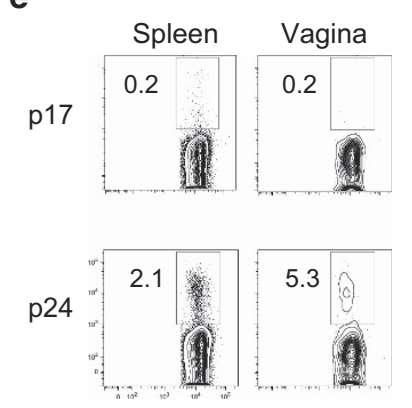

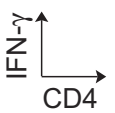

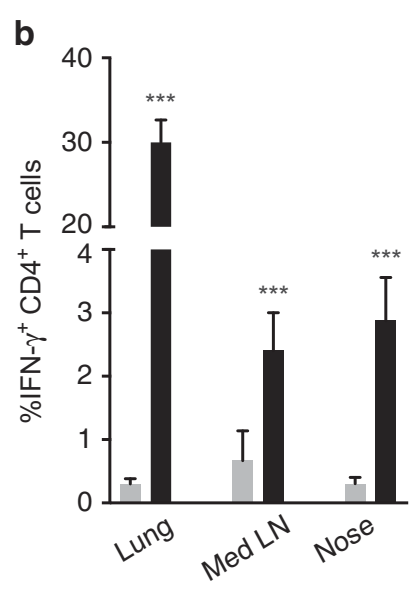

d

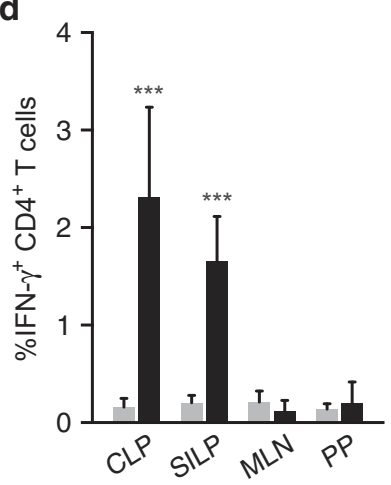

f

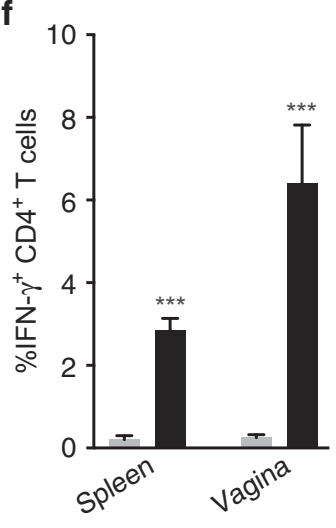

Figure 2 Following intranasal immunization, p24 immune responses are generated within nasal and lung tissues and disseminate to mucosal and systemic sites. (a-f) C57BI/6 mice were vaccinated IN with $\alpha$-CD205-p24 fusion mAb $(5 \mu \mathrm{g})$ and poly ICLC (50 $\mu \mathrm{g})$ and p24-specific immune responses were evaluated 1 week post boost. (a) FACS plots from a representative experiment, illustrating the induction of IFN- $\gamma^{+} \mathrm{CD} 4^{+}$cells in the lung, mediastinal LN (Med LN) and nose. (b) Mean data from three independent experiments (5 mice per group). Statistical comparisons to p17 (control) are shown. (c) FACS plots from a representative experiment, illustrating the induction of IFN- $\gamma^{+} \mathrm{CD} 4^{+}$cells in the GI effector (CLP and SILP) and inductive (Peyer's patch- PP and mesenteric LN-MLN) sites. (d) Mean data from three independent experiments (5 mice per group). Statistical comparisons to $\mathrm{p} 17$ (control) are shown. (e) FACS plots from a representative experiment, illustrating the induction of IFN- $\gamma^{+} \mathrm{CD} 4^{+}$cells in the spleen and vaginal mucosa. (f) Mean data from three independent experiments ( 5 mice per group). Statistical comparisons to $p 17$ (control) are shown. Error bars show mean \pm s.d. ${ }^{\star \star \star} P<0.001$. CLP, colonic lamina propria; FACS, fluorescence activated cell sorting; IN, intranasally; IP, intraperitoneally; poly ICLC, poly-L-lysine and carboxymethylcellulose; SILP, small intestinal lamina propria.

of these cells, considered as a possible correlate of vaccineinduced protection, ${ }^{7}$ was assessed. Mononuclear cells were isolated from the SILP, spleen, and Med LN of vaccinated mice and re-stimulated with either p24 or p17 peptide pools and
$\alpha$-CD28 $\left(1 \mu \mathrm{g} \mathrm{ml}^{-1}\right)$ for $20 \mathrm{~h}$. Post restimulation the supernatant was collected and cytokine profiles determined using a Bio-Plex mouse cytokine immunoassay. The use of multiplexed enzyme-linked immunosorbent assay (ELISA) allowed us 
a

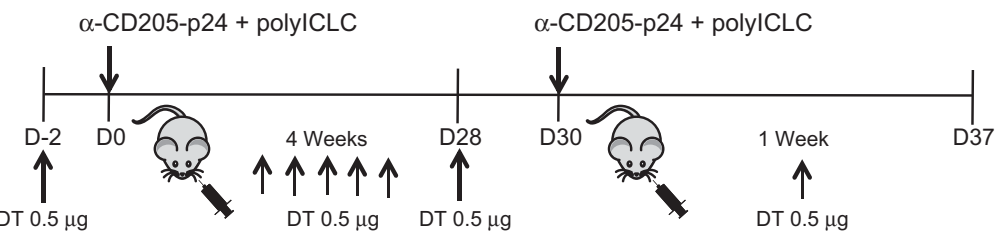

b
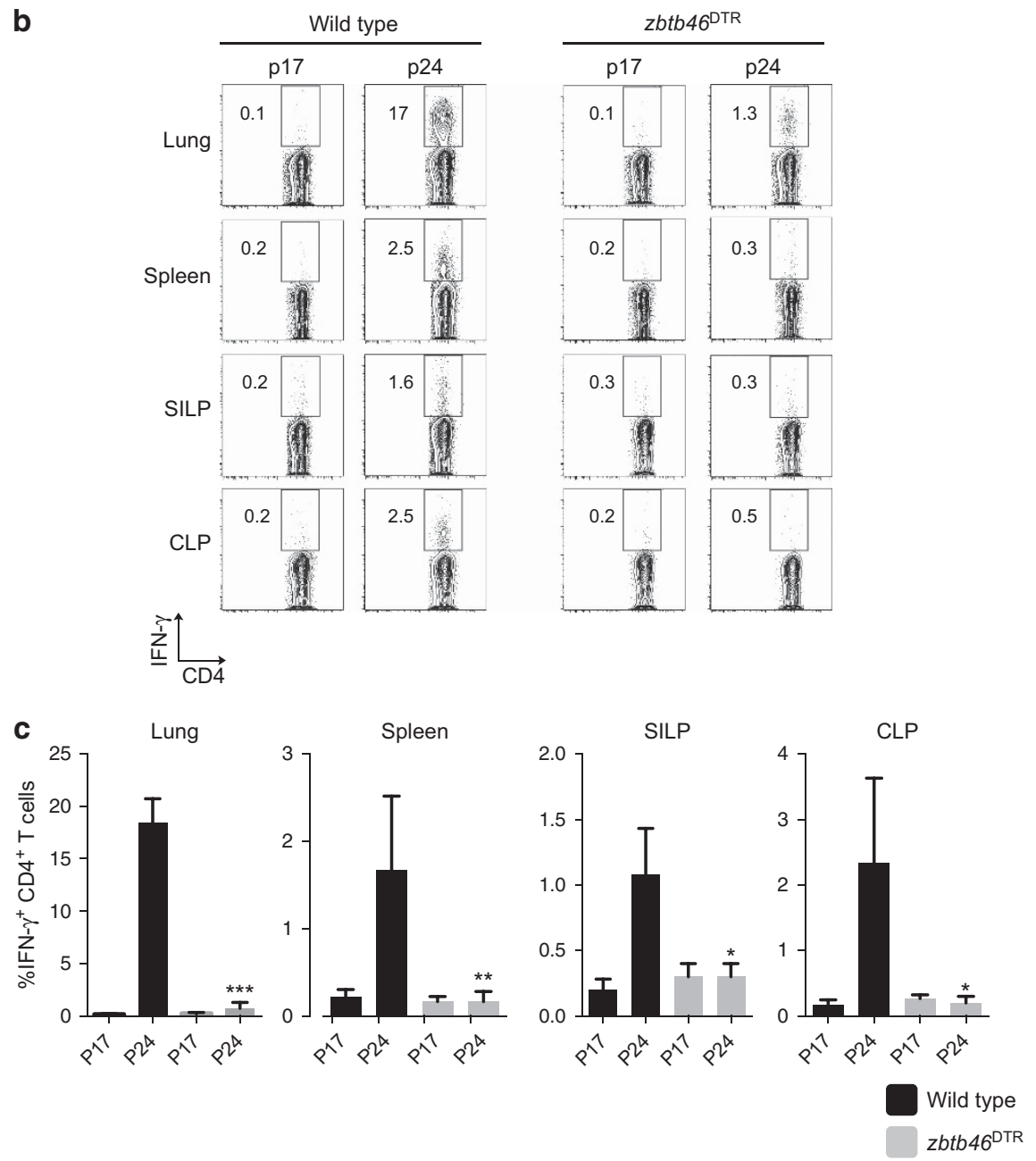

Figure 3 Classical DCs are essential for inducing systemic and mucosal immune responses to intranasal immunization. Wild type (WT) and $z b t b 46^{\mathrm{DTR}}$ mice were immunized IN with $\alpha$-CD205-p24 fusion mAb $(5 \mu \mathrm{g})$ and poly ICLC $(50 \mu \mathrm{g})$ in a prime-boost manner. Diphtheria toxin (DT), $(0.5 \mu \mathrm{g})$ was administered IP, $48 \mathrm{~h}$ before immunization and every 5 days post vaccination. Additional doses of DT were administered on days 28 and 4 days post boost. IFN- $\gamma$ secretion in response to HIV gag-p24 (immunizing) or p17 (control) peptide pools was evaluated 1 week post boost by intracellular cytokine staining. (a) Shows the schema of immunization. (b) FACS plots from a representative experiment, illustrating the induction of IFN- $\gamma^{+} \mathrm{CD} 4{ }^{+}$cells in the lung, spleen, SILP, and CLP. (c) Mean data from three independent experiments (5 mice per group) is shown. Statistical comparisons between p24 levels in WT and $z b t b 46^{\mathrm{DTR}}$ mice are shown. Error bars show mean \pm s.d. ${ }^{\star} P<0.05,{ }^{\star \star} P<0.01,{ }^{* \star *} P<0.001$. CLP, colonic lamina propria; FACS, fluorescence activated cell sorting; IN, intranasally; IP, intraperitoneally; poly ICLC, poly-L-lysine and carboxymethylcellulose; SILP, small intestinal lamina propria.

simultaneous detection of multiple cytokines from a relatively small $(\sim 50 \mu \mathrm{l})$ volume of the sample. Therefore, we chose this method over the conventional, FACS-based study of intracellular cytokines. IN immunization induced highly polyfunctional $\mathrm{CD} 4{ }^{+} \mathrm{T}$ cells within local (Med LN), systemic (spleen), and gastrointestinal (SILP and CLP) sites (Figure 5). Specifically, IFN- $\gamma$, IL-2, IL-6, IL-17a, and IL-1 $\beta$-cytokines, as well CC chemokines- MIP- $1 \alpha$ and MIP- $1 \beta$ were induced post immunization. Cell yield in the colon was low and was insufficient to provide reliable data. Thus, data from CLP were not included. Thus, IN immunization with DC-targeted $\alpha$-CD205-p24 vaccine produced highly polyfunctional $\mathrm{T}$ cells in the GI tract.

\section{Dendritic cell targeting induces long-term memory CD4 ${ }^{+}$ $T$ cells in the Gl tract}

To test whether long-term memory could be detected within the intestinal tract, we examined recall responses in mice immunized with the DC-targeted or untargeted vaccine after 24 weeks of vaccination. Effector memory cells, i.e., T cells 

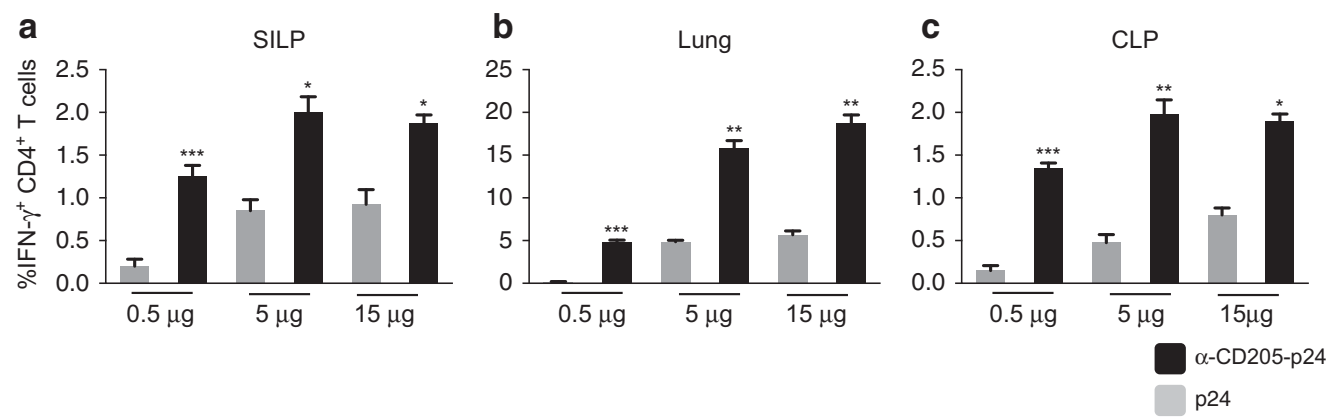

Figure 4 DC targeting enhances the amplitude of anti-p24 immune responses in the GI tract compared with untargeted protein vaccination. C57BI/6 mice were immunized IN with polyICLC, plus either $\alpha$-CD205-p24 fusion mAb or untargeted p24 protein, both delivered IN in a prime-boost regimen, in escalating doses of $0.5,5$ and $15 \mu \mathrm{g}$. Mean data from three independent experiments ( 5 mice per group) is shown in (a-c) where in response to HIV gagp24 or p17 peptide pools, IFN- $\gamma^{+}$CD4 ${ }^{+}$T cells were quantified in the SILP (a), lung (b) and CLP (c). Background (p17) subtracted p24 data are shown. In

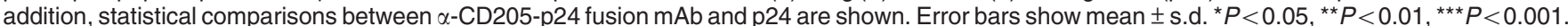
CLP, colonic lamina propria; DC, dendritic cell; GI, gastrointestinal; IN, intranasally; poly ICLC, poly-L-lysine and carboxymethylcellulose; SILP, small intestinal lamina propria.

producing IFN- $\gamma$ were readily detected within the spleen, lung, SILP, and CLP of mice immunized with the DC-targeted vaccine (albeit at a lower frequency in the spleen than at mucosal sites). In contrast, untargeted p 24 vaccination induced significantly lower levels of effector memory cells within the GI compartments or lungs and virtually undetectable levels in the spleen at 24 weeks (Figure 6a-c). Therefore, DC targeting induces long-term memory against $\mathrm{p} 24$ protein in the intestinal tissues.

\section{Heterologous $\alpha$-CD205-p24 prime, NYVAC gag/pol/nef boost immunization, generates p24-specific $\mathrm{CD}^{+} \mathrm{T}$ cells in the systemic and mucosal compartments}

$\alpha$-CD205-p24 prime-boost vaccine used in the present study raised concerns regarding generation of $\mathrm{HIV}$-specific $\mathrm{CD} 4{ }^{+}$ $\mathrm{T}$ cells in the GI and vaginal tracts, potentially with enhanced susceptibility to the virus. ${ }^{32}$ Therefore, we wanted to develop a platform to generate $\mathrm{HIV}$-specific $\mathrm{CD}^{+}{ }^{+} \mathrm{T}$ cells at these mucosal sites and performed heterologous prime-boost experiments (priming with $\alpha$-CD205-p24 followed by a NYVAC-gag boost). We hypothesized that vaccinating with DEC-205 targeted vaccine would generate p24-specific helper $\mathrm{T}$ cells, which could then enhance the induction of $\mathrm{CD} 8{ }^{+} \mathrm{T}$-cell responses using a poxvirus vector such as NYVAC. ${ }^{33}$ Using a heterologous prime-boost immunization regimen, first generation $\mathrm{C} 57 \mathrm{Bl} / 6$ and $\mathrm{Balb} / \mathrm{c}$ offspring (F1 mice) were immunized with $25 \mu \mathrm{g}$ of $\alpha$-CD40, $50 \mu \mathrm{g}$ of polyICLC, and $5 \mu \mathrm{g}$ of $\alpha$-CD205-p24 delivered IN For these experiments, F1 hybrid mice (first generation $\mathrm{C} 57 \mathrm{Bl} / 6$ and Balb/c offspring) were used as the CD8 response is directed to a defined gag 197-205 peptide presented only on $\mathrm{H}-2 \mathrm{~d}$ but not $\mathrm{H}-2 \mathrm{~b}$ as shown previously. ${ }^{34}$ The F1 mice were immunized with $25 \mu \mathrm{g}$ of $\alpha$-CD40, $50 \mu \mathrm{g}$ of polyICLC, and $5 \mu \mathrm{g}$ of $\alpha$-CD205-p24 delivered IN Previous observations have demonstrated that a combination of a TLR ligand and an agonist $\alpha$-CD 40 antibody elicited stronger immunity. ${ }^{19,35}$ Therefore, we immunized with a combination of $\alpha$-CD40 and PolyICLC in these experiments. Four weeks later the mice were administered $10^{7}$ p.f.u. of
NYVAC-gag/pol/nef, delivered IN (Figure 7a). In addition IP immunization was also assessed (Supplementary Figure 1 online). 14 days post boost, IFN- $\gamma^{+} \mathrm{CD} 8^{+}$T-cell responses were observed in the lung, spleen, blood, and vaginal tract of the IN immunized mice (Figure $\mathbf{7 b}$ and $\mathbf{c}$ ). Unfortunately, poor viability of intestinal mononuclear cells precluded conclusions to be drawn in two of three experiments of the IN immunized group. However, robust levels of intestinal IFN- $\gamma^{+} \mathrm{CD} 8{ }^{+}$ $\mathrm{T}$ cells were detected in the GI tract of the IP immunized mice. Therefore, we conclude from these experiments that while $\alpha$-CD205-p24 prime-boost immunization generated predominantly $\mathrm{CD} 4{ }^{+}$T-cell responses, with a heterologous $\alpha$-CD205-p24 prime, NYVAC boost immunization regimen, we were able to generate gag-p24-specific $\mathrm{CD} 8{ }^{+} \mathrm{T}$ cells within the systemic compartment as well as mucosal sites.

\section{DISCUSSION}

The global impact of HIV infection is staggering. Since it was recognized over 34 years ago, ${ }^{36}$ the HIV pandemic has resulted in the infection of $\sim 60$ million people worldwide, nearly half of who have died from the disease. It is widely accepted that while substantial advances have been made in the field of HIV therapeutics, an effective HIV vaccine would be the optimum solution for the ultimate control of the global AIDS pandemic. $^{37}$

The present study was guided by three principles. First, given the profound effect of HIV-1 infection on GI-resident CD4 ${ }^{+}$ $\mathrm{T}$ cells ${ }^{1,3}$ our goal was to induce HIV-1-specific immune responses in the GI mucosa. Second, targeting DC-specific lectins and endocytic receptors has been demonstrated to enhance the potency, magnitude, and longevity of vaccineinduced systemic immune responses, ${ }^{12,19,38,39}$ therefore, we wanted to adopt a DC-targeted approach to enhance mucosal immunity. Third, as mucosal routes of vaccine delivery are superior to systemic routes in inducing mucosal immune responses, ${ }^{28,40-42}$ we wanted to immunize across a mucosal surface to induce HIV-1-specific cells in the gut. Combined, here we provide the first study of a mucosally delivered, 
a

IFN- $\gamma$

$\mathrm{IL}-17$

IL-6
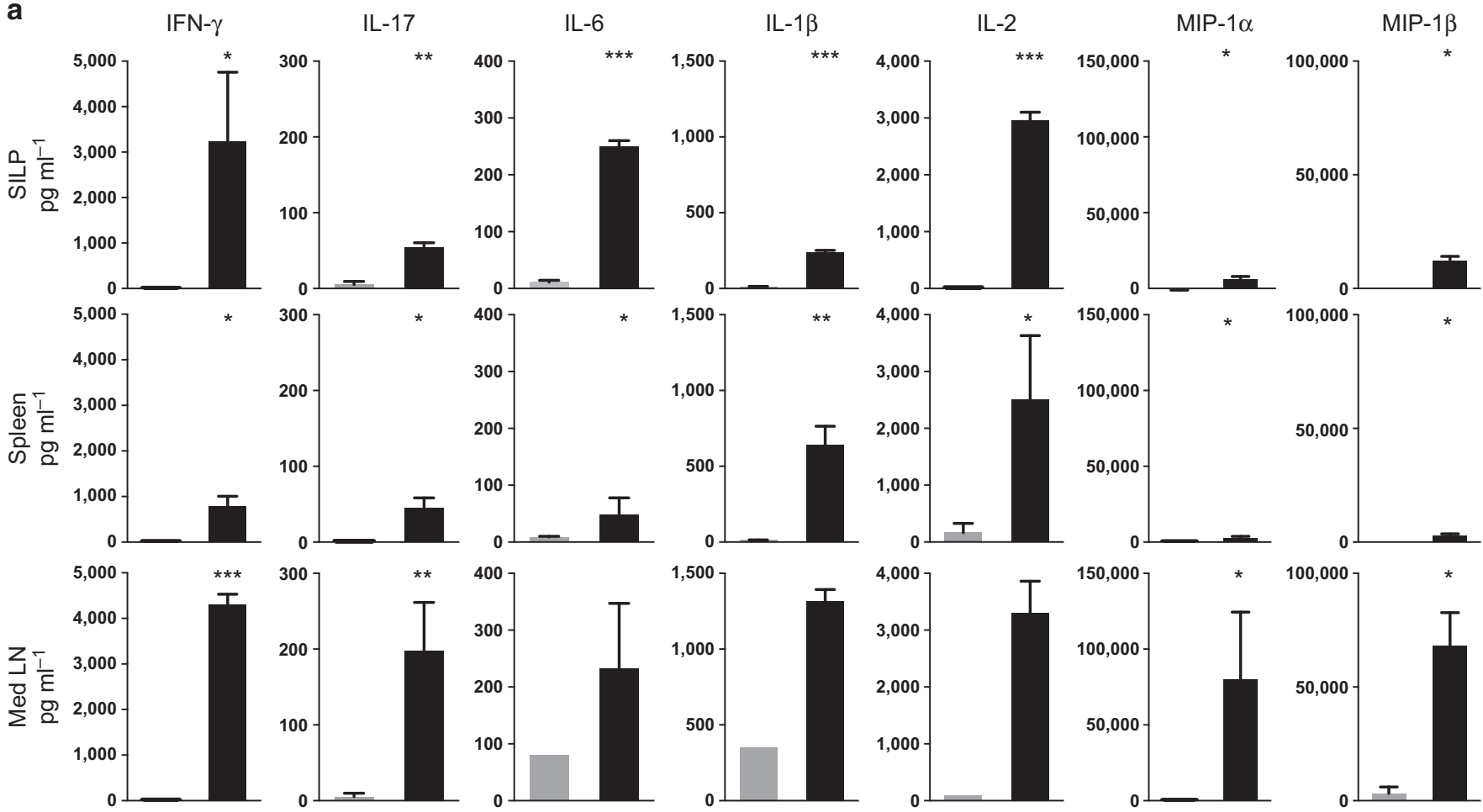

p17

p24

Figure 5 Intranasal immunization with $\alpha$-CD205-p24 induced predominantly antigen-specific Th1 and Th17 responses in the GI tract. C57BI/6 mice were immunized IN with $\alpha$-CD205-p24 fusion mAb $(5 \mu \mathrm{g})$ and poly ICLC $(50 \mu \mathrm{g})$ in a prime-boost regimen. One-week post boost, mononuclear cells were isolated from the SILP, spleen and Med LN and re-stimulated with either p24 or p17 peptide pools and $\alpha-C D 28\left(1 \mu \mathrm{g} \mathrm{ml}{ }^{-1}\right)$ for $20 \mathrm{~h}$. Multiplexed ELISA was used to quantify the levels of secreted IFN- $\gamma$, IL-17, IL-6, IL-1 $\beta$, IL-2, MIP-1 $\alpha$ and MIP-1 $\beta$. Mean data from two individual experiments is shown (5 mice per experiment). Statistical comparisons to $p 17$ control are shown. Error bars show mean \pm s.d. ${ }^{\star} P<0.05,{ }^{\star \star} P<0.01,{ }^{\star \star \star} P<0.001$. ELISA, enzyme-linked immunosorbent assay; GI, gastrointestinal; IFN, interferon; IL, interleukin; IN, intranasally; poly ICLC, poly-L-lysine and carboxymethylcellulose; SILP, small intestinal lamina propria.

DC-targeted vaccine to generate HIV-1-specific immune responses in the GI tract.

Although to date no evidence exists that $\mathrm{CD}^{+}{ }^{+} \mathrm{T}$-cell activation or vaccine-induced $\mathrm{CD}_{4}{ }^{+} \mathrm{T}$ cells result in heightened HIV-1 acquisition or viremia after infection, ${ }^{43,44}$ $\alpha$-CD205-p24 prime-boost vaccine used in the present study raises concerns regarding generation of $\mathrm{HIV}$-specific CD4 ${ }^{+} \mathrm{T}$ cells in the GI and vaginal tracts, potentially with enhanced susceptibility to the virus. ${ }^{32}$ In particular, our data need to be evaluated in the context of the STEP (HVTN 502/Merck 023) Trial-a multicenter phase IIb study of Ad5 HIV-1 clade B gag/ $\mathrm{pol} /$ nef vaccine compared with placebo. ${ }^{45}$ The study was halted prematurely in 2007 due to lack of vaccine efficacy despite inducing IFN- $\gamma$ ELISPOT responses in the peripheral blood. A similar Phambili/HVTN 503 study, also using the Merck Ad5 vaccine did not reveal increased susceptibility to HIV as was seen in the Step Trial, but the study was scientifically inconclusive owing to premature discontinuation of the trial. ${ }^{46}$ Post hoc analyses of the step trial revealed a higher rate of HIV infection in uncircumcised men, seropositive for Ad5 before vaccine administration. A number of theories were proposed to understand the correlates of increased susceptibility to HIV seen in this subgroup of step trial volunteers. These included the possibility that the vaccine increased the number of activated $\mathrm{CD}^{+} \mathrm{T}$ cells in the peripheral blood, lymphoid tissue or mucosal sites and created potential targets for HIV-1. Subsequent analyses of peripheral blood T cells have debunked the possibility that expansion, activation or homing of Ad5-specific $\mathrm{CD}^{+}{ }^{+} \mathrm{T}$ cells was responsible for increased susceptibility to HIV seen in the Step Trial. ${ }^{47,48}$ As mucosal sampling was not included in the Step Trial, analyses of the mucosa became available recently from a different study where rhesus macaques were immunized with rAd5-gag/pol/nef vaccine (rAd5), similar to the vaccine used in the Step Trial. This study also has revealed no increase in the phenotype, frequency or trafficking of Ad5-specific CD $4^{+}$T lymphocytes to mucosal target sites following rAd5 vaccination of rhesus monkeys with baseline Ad5 immunity. ${ }^{49}$ These studies provide evidence against the hypothesis that recruitment of vectorspecific $\mathrm{CD}^{+}{ }^{+} \mathrm{T}$ cells to mucosal sites led to increased HIV-1 acquisition in Ad5 seropositive, uncircumcised vaccinees in the step study. A number of additional findings that have emerged 
a

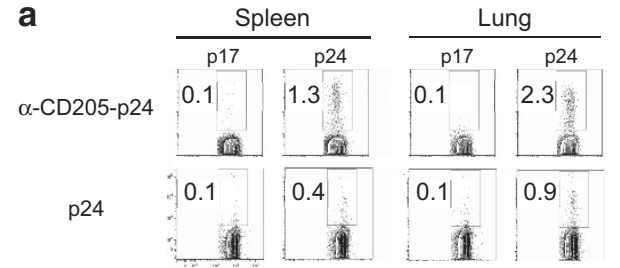

b
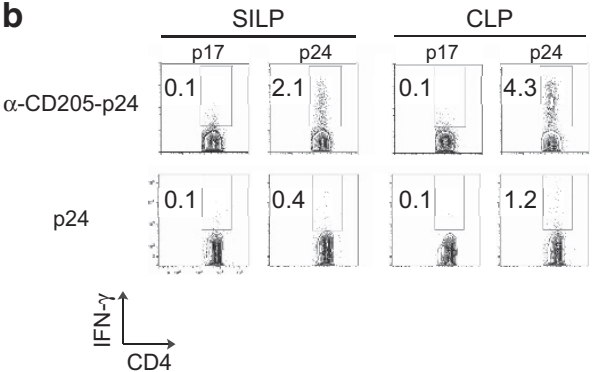

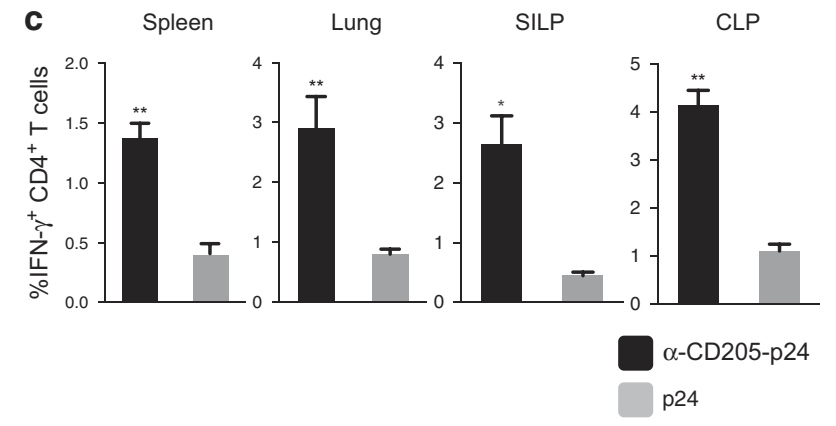

Figure $6 \alpha$-CD205-p24 vaccine delivered IN induces long-term memory in effector sites of the GI tract. C57BI/6 mice were immunized in a prime-boost regimen with polylCLC plus either $\alpha$-CD205-p24 fusion mAb $(5 \mu \mathrm{g})$ or p24 (15 $\mu \mathrm{g}$, the highest dose of untargeted p24 vaccine was chosen). Mice were killed 25 weeks post boost and lymphocytes were isolated from the spleen, lung, and the effector sites (SILP and CLP) of the GI tract. IFN- $\gamma^{+}$CD4 ${ }^{+}$T cells were examined by flow cytometry. (a,b) FACS plots from a representative experiment showing antigen-specific IFN- $\gamma^{+} \mathrm{CD} 44^{+} \mathrm{T}$ cells in the spleen, lung, SILP, and CLP. (c) Mean data from three independent experiments is shown (5 mice per group). Background (p17) subtracted p24 data are shown. Statistical comparisons between $\alpha$-CD205-p24 fusion mAb and p24 are shown. Error bars show mean \pm s.d. ${ }^{*} P<0.05,{ }^{* *} P<0.01,{ }^{* * *} P<0.001$. CLP, colonic lamina propria; ELISA, enzyme-linked immunosorbent assay; FACS, fluorescence activated cell sorting; GI, gastrointestinal; IFN, interferon; IN, intranasally; poly ICLC, poly-L-lysine and carboxymethylcellulose; SILP, small intestinal lamina propria.

from the analyses of step trial data that may explain the lack of vaccine efficacy. These include reduced vaccine-specific immunity in Ad5 seropositive individuals, ${ }^{45}$ narrow epitope recognition by $\mathrm{CD}_{8}{ }^{+} \mathrm{T}$ cells, ${ }^{44}$ and the induction of intestinal microbiota polyreactive HIV non-neutralizing gp-41 reactive antibody repertoire response to HIV Env DNA- rAD5 vaccine. ${ }^{50}$ Another key feature that has been highlighted by the step trial is the fact that HIV vaccine efficacy studies need to incorporate evaluation of mucosal immune responses in their study design. ${ }^{44}$ This is an aspect that our study attempts to address.

In contrast to the Step Trial, The RV 144 efficacy trial conducted in Thailand provided encouraging evidence that an HIV vaccine could provide modest level of protection against HIV acquisition-31.2\% at 42 months of follow up. ${ }^{43}$ Immune correlates of protection demonstrated that IgG antibodies to V1V2 loops in the HIV envelope correlated inversely with the rate of HIV-1 infection. ${ }^{51}$ Notably, again HIV-specific CD4 ${ }^{+}$ $\mathrm{T}$ cells were not associated with infection risk in these analyses. In contrast, studies done on a subgroup of RV 144 vaccine recipients confirmed the presence of $\mathrm{V} 2$ specific, polyfunctional effector $\mathrm{CD}^{+}{ }^{+} \mathrm{T}$ cells. ${ }^{52}$

Further proof that HIV-specific $\mathrm{CD} 4{ }^{+} \mathrm{T}$ cells are not associated with increased risk of disease acquisition comes from the pre-exposure prophylaxis initiative trial. In this study, T-cell responses to HIV-1 gag, protease, integrase, reverse transcriptase, vif, and nef antigens were examined in exposedsero negative subjects. IFN-g ${ }^{+} \mathrm{CD} 4^{+}$and $-\mathrm{CD} 8^{+}$responses against vif and integrase were associated with reduced HIV-1 infection risk. ${ }^{53}$

Together, based on these data, we infer that although there has been a theoretical risk, the abundance of scientific evidence refutes the claim that HIV-specific $\mathrm{CD}^{+}{ }^{+} \mathrm{T}$ cells enhance susceptibility to HIV-1 infection. In fact, we would argue that as the vast majority of neutralizing antibodies and cytotoxic $\mathrm{T}$ cells are critically dependent on $\mathrm{CD} 4^{+}$T-cell help, inducing specific, potent, broad, and long-lived $\mathrm{CD} 4^{+} \mathrm{T}$-cell response will be essential in the HIV-1 vaccine effort. This was the rationale behind the heterologous prime-boost experiments (priming with $\alpha$-CD205-p24 followed by a NYVAC-gag boost) in our study. We hypothesized that vaccinating with DEC-205 targeted vaccine would generate robust levels of p24-specific helper $\mathrm{T}$ cells, which could then enhance the induction of $\mathrm{CD}^{+}{ }^{+} \mathrm{T}$-cell responses using a poxvirus vector such as NYVAC, ${ }^{33}$ A recent phase $1 \mathrm{~b}$ clinical trial with recombinant adenovirus 5 -vectored prime, followed by NYVAC boost showed enhanced vaccine immunogenicity and further validated our rationale. ${ }^{54}$ In confirmation of our hypothesis, we detected significant numbers $\left(\sim 10-20 \%\right.$ of all CD8 ${ }^{+}$ $\mathrm{T}$ cells) of $\mathrm{p} 24$-specific $\mathrm{CD} 8{ }^{+} \mathrm{T}$ cells in both the GI tract and the vaginal mucosa. This is the first demonstration of DEC-205 prime, NYVAC boost vaccination and given the robust generation of $\mathrm{CD} 8{ }^{+} \mathrm{T}$ cells at mucosal surfaces.

The migration of cells to the gut in response to sensitization in the lung (and vice versa) led to the proposal of a "common mucosal immunological system" by Bienenstock et al. ${ }^{55}$ in 1978. In support of this hypothesis, we have recently demonstrated that intranasal vaccination can target lung DCs to induce gut homing receptors $\alpha 4 \beta 7$ and CCR9 and recruit vaccine primed, antigen specific, T cells to the GI tract. ${ }^{29}$ Further, administration of an adjuvant such as polyICLC appeared to boost the expression of $\alpha 4 \beta 7$-on $\mathrm{T}$ cells following IN vaccination. ${ }^{29}$ In the present study we show that an IN 
a

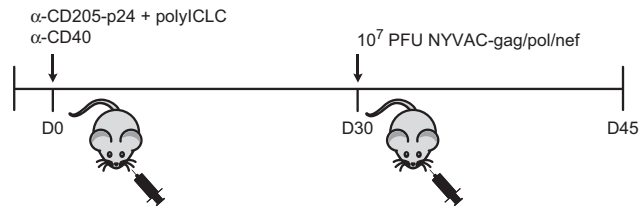

b
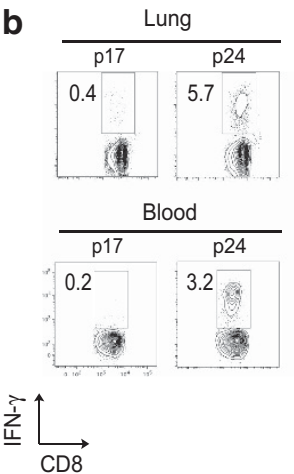

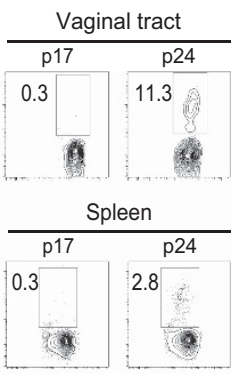

C

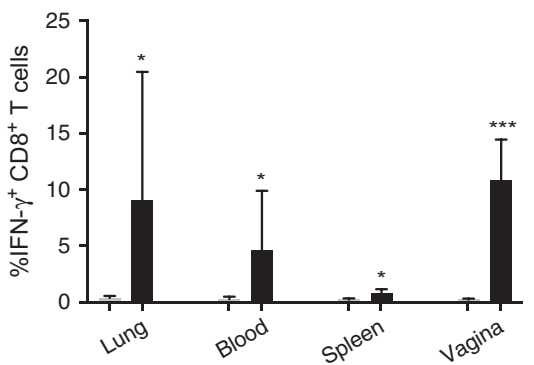

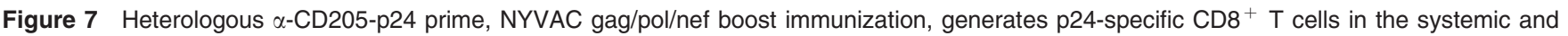
mucosal compartments. F1 hybrid (cross between BALB/c females and C57BI/6 males; heterozygous at all loci) mice were immunized with $\alpha$-CD205-p24 fusion mAb $(5 \mu \mathrm{g})$, poly ICLC $(50 \mu \mathrm{g})$, and $\alpha$-CD40 $(25 \mu \mathrm{g})$. After 4 weeks, the mice were administered $10^{7} \mathrm{p} . f . u$. NYVAC gag/pol/nef delivered IN. After 2 weeks of boost, IFN- $\gamma$ secretion was evaluated in CD8 ${ }^{+}$T cells. (a) Shows the schema of immunization. (b) FACS plots from a representative experiment, illustrating the induction of IFN $-\gamma^{+} \mathrm{CD}^{+}$cells in the lung, vaginal tract, blood, and spleen. (c) Mean data from three independent experiments ( 5 mice per group) summarizing IFN- $\gamma^{+} \mathrm{CD}^{+} \mathrm{T}$ cells in the lung, blood, spleen, and vagina. Statistical comparisons to p17 (control) are shown. Error bars show mean \pm s.d. ${ }^{*} P<0.05$, ${ }^{* * *} P<0.001$. CLP, colonic lamina propria; ELISA, enzyme-linked immunosorbent assay; FACS, fluorescence activated cell sorting; GI, gastrointestinal; IFN, interferon; IN, intranasally; p.f.u., plaque-forming unit; poly ICLC, poly-L-lysine and carboxymethylcellulose; SILP, small intestinal lamina propria.

delivered $\alpha$-CD205-p24 vaccine induces gag-p24-specific cells in the inductive sites of the upper (nose-associated lymphoid tissue) and lower (Med LN) respiratory tract but not the GI tract (PP and MLN). Interestingly, in addition to effector respiratory sites (lung), gag-p24-specific $\mathrm{T}$ cells could also be detected in the effector sites of GI (SILP and CLP) and genital (vaginal mucosa) tracts. Although we did not test for the expression of $\alpha 4 \beta 7$ (targeting to the gut) or $\alpha 4 \beta 1$ (targeting to the vaginal mucosa), our data echo recent findings by Stary et al. ${ }^{56}$ who show that nasal vaccination against Chlamydia trachomatis targets $\mathrm{CD} 4^{+} \mathrm{T}$ cells to the vaginal mucosa and offers protection against genital chlamydia infection. It follows therefore, that IN vaccine-induced immune responses, generated locally within the upper and lower respiratory tracts are disseminated widely to other mucosal sites. Thus, the present study provides further functional evidence of IN vaccine-induced DC-mediated mucosal cross talk.

A number of immunomodulatory agents including toxin based adjuvants, cytokines, CpG DNA, $\alpha$-Gal-cer, chitosan, and non-replicative delivery systems, reviewed in ref 57 have been tested as mucosal adjuvants. We chose microbial mimic and TLR-3 ligand, poly ICLC as an adjuvant based on its enhanced potency compared with other adjuvants when co-administered with protein antigens. ${ }^{22}$ Furthermore, polyICLC has an established safety record in cancer patients ${ }^{58-60}$ and, in a recent study by our lab, polyICLC, administered subcutaneously to a group of human volunteers demonstrated excellent safety. ${ }^{61}$ This combined with the data presented here supports the use of polyICLC as a mucosal adjuvant for further studies.

Our study establishes that intranasal vaccine-induced immunity is mediated by $z b t b 46$-dependent classical DCs. In addition, two other features of DC targeting with intranasal vaccines stand out here. First, DC-targeting boosts the amplitude of vaccine-induced mucosal immunity. Second, DC-targeting results in a striking increase in the longevity of mucosal immune responses. We speculate that enhanced longevity of DEC-205-targeted immune response could be due to a stronger priming effect. Alternatively, as DEC-205 is expressed in the intestinal epithelium, ${ }^{62}$ we hypothesize that epithelial DEC-205 signals could maintain the longevity of DEC-205 DC-primed mucosal immune responses. We are in the process of testing this hypothesis and if proven, this could make DEC-205 targeting particularly relevant for mucosal vaccines.

Several characteristics of T cells such as phenotype, function, antigen specificity, and MHC restriction have been investigated as potential correlates of immune protection after vaccination. ${ }^{7}$ Recent data, however, suggests that the quality of the immune response, measured through increased levels of antigen-specific polyfunctional $\mathrm{T}$ cells capable of producing multiple, relevant cytokines, is a better correlate of sustained protective immunity. ${ }^{63}$ The use of multiplexed ELISA allowed us simultaneous detection of multiple cytokines from a relatively small ( $\sim 50 \mu \mathrm{l})$ volume of the sample. Therefore, we chose this method over the conventional, FACS-based study of 
intracellular cytokines. Our study demonstrates that IN vaccination with $\alpha$-CD205-p24 vaccine generated polyfunctional T cells, both systemic and mucosal, capable of producing $\mathrm{T}_{\mathrm{H}} 1, \mathrm{~T}_{\mathrm{H}} 2$, and $\mathrm{T}_{\mathrm{H}} 17$ cytokines as well as $\beta$-chemokines. Although vaccine-induced IFN- $\gamma$ and IL- 2 production is perhaps best studied, there is evidence that $\beta$ chemokines such as MIP- $1 \alpha$ and MIP-1 $\beta$ are associated with a better clinical status in HIV-1 infected patients. ${ }^{64}$ In addition, IL-17 producing $\mathrm{CD}^{+}{ }^{+} \mathrm{T}$ cells have been associated with protective efficacy of vaccines against tuberculosis ${ }^{65}$ and rotavirus infections, ${ }^{66}$ whereas reduced intestinal IL-17a production is associated with loss of mucosal integrity and with SIV disease progression in rhesus macaques. ${ }^{67,68}$ The induction of IL-17 producing cells by our $\alpha$-CD205-p24 vaccine is particularly interesting in this context and worthy of further examination.

Humoral immunity can completely suppress viremia in humanized mice, ${ }^{69,70}$ SIV-infected rhesus macaques ${ }^{71}$ and, in combination with viral inducers, decrease rebound from latent reservoirs of HIV-1 in humanized mice. ${ }^{72}$ In addition, as discussed above, the RV 144 Thai trial ${ }^{43}$ has demonstrated that vaccine recipients who produced V2-loop antibodies were $31 \%$ less likely to get HIV-infected. ${ }^{73}$ Therefore, although the focus of the present study was induction of $\mathrm{T}$ cell immunity, we also investigated vaccine-induced humoral response in the GI mucosa. Notably, antigen targeting to DCs has previously been shown to elicit long-lived T-cell help for antibody responses. ${ }^{74}$ Our study found that the IN administered, DC-targeted vaccine-induced antigen-specific IgA secreting B cells in the intestinal lamina propria. We are planning a more detailed investigation on GI humoral immunity elicited by DC-targeted vaccines.

We would like to mention an important caveat here- how these findings will translate to protection against human infection are unclear at this point and additional studies of in-vivo protection are needed. However, to our knowledge, there are no challenge models to test the efficacy of vaccineinduced, HIV-specific immune responses within the murine GI tract. The vaccinia-gag model, previously used in the lab ${ }^{19}$ is less relevant for delivery across the GI mucosa. As more studies examine the induction of $\mathrm{HIV}$-specific immune responses in the GI tract, the creation of a GI-specific challenge model will become increasingly relevant.

In summary, our study is the first demonstration of a DC cell targeted, mucosally delivered vaccine to induce HIV-1-specific immunity in the GI tract. The data presented herein offers insights into future research in identifying preventative strategies not only against HIV-1 infection but also against other enteric and pulmonary pathogens.

\section{METHODS}

Mice. $\mathrm{C} 57 \mathrm{Bl} / 6$ mice (B6) and Balb/c mice were purchased from Taconic Labs or bred at the Rockefeller University. F1 hybrid mice (cross between BALB/c females and C57Bl/6 males; heterozygous at all loci), were bred at in-house. $Z b t b 46^{D T R}$ mice were kindly provided by Dr M. Nussenszweig (Rockefeller University, New York). All mice were maintained in specific pathogen-free conditions and used at 6-8 weeks unless otherwise specified. Protocols were approved by the Rockefeller University Animal Care and Use Committee.

Construction and production of fusion mAbs. DNA for HIV gag-p24 (aa 133-363 derived from HIV isolate $\mathrm{BH} 10$ ) was cloned in frame into the $\mathrm{COOH}$ terminus of the heavy chains of $\alpha$-mouse-DEC-205 as described previously. ${ }^{19}$ The fusion $\alpha$-CD205-p24 mAb was produced by transient transfection (calcium phosphate) in $293 \mathrm{~T}$ cells in serum-free DMEM supplemented with Nutridoma SP (Roche Applied Science, Indianapolis, IN). The mAbs were purified on protein G columns (GE Healthcare Bio-Sciences, Pittsburgh, PA) and characterized by polyacrylamide gel electrophoresis/PAGE and western blotting using $\alpha$-mouse IgG1-HRP (Southern Biotech, Birmingham, AL) or HRP- $\alpha$-gag-p24 (ImmunoDiagnostics, Espoo, Finland). mAb binding was verified on $\mathrm{CHO}$ cells stably transfected with the respective receptor by FACS using phycoerythrin-conjugated goat $\alpha$-mouse IgG (Jackson ImmunoResearch, West Grove, PA). Unconjugated $\alpha$-DEC-205 mAb expressed by stably transfected $\mathrm{CHO}$ cells was similarly purified. Recombinant NYVAC-encoding HIV BX08gp120-IIIBGag/Pol/Nef is a replication incompetent vector, kindly provided by Dr Giuseppe Pantaleo (Centre Hospitalier Universitaire Vaudois (CHUV) Lausanne, Switzerland) and prepared as previously described. ${ }^{75}$

Soluble gag-p24 protein. Soluble FLAG gag-p24 protein $^{76}$ was expressed by $\mathrm{CHO}$ cells and purified from culture supernatant using anti-FLAG M1 Affinity gel (Sigma-Aldrich, St Louis, MO) following the manufacturer's instructions. All proteins had $<0.125$ endotoxin units per $\mu \mathrm{g}$ using a Limulus Amebocyte Lysate assay, QCL-1000 (Bio Whittaker, Walkersville, MD).

HIV gag peptides. Overlapping (staggered by 4 aa) gag p17 and p24 15-mer peptides were obtained from the NIH AIDS Reference Reagent Program (catalog no. 8117). Peptides, including the $\mathrm{H}-2 \mathrm{~K}^{\mathrm{d}}$ binding peptide p24 197-205 (ref. 34), were also synthesized by the Proteomics Resource Center at The Rockefeller University. As previously described, ${ }^{19}$ the 30 - and 60-member gag p17 and p24 libraries were divided into 3 and 5 pools of 9 to 12 peptides, respectively. The respective gag p17 peptide pools span from aa 1-51 (pool 1), aa 41-91 (pool 2), and aa 81-135 (pool 3) of the HIV gag p17 protein. The respective gag-p24 peptide pools span from aa 125-183 (pool 1), aa 173-231 (pool 2), aa 221-279 (pool 3), aa 269-327 (pool 4), and aa 317-363 (pool 5) of the HIV gag-p24 protein. Response to individual pools has been mapped previously in our lab. ${ }^{19}$ Also, previous work from the lab has demonstrated that $\mathrm{CD} 8{ }^{+} \mathrm{T}$-cell responses elicited by pooled p24 peptides were comparable to the 197-205 nonamer peptides. ${ }^{15}$ Hence, in the present study, we combined all three p17 peptide pools and all five p24 peptide pools together while testing for recall responses.

Immunization. Mice were injected by various routes including IN, IP, IV, IM or SC (in the hind footpads) with the indicated doses of fusion $\alpha$-CD205-p24 mAb, unconjugated $\alpha$-CD205-empty mAb, or HIV gag-p24 protein along with stimuli for DC maturation-polyICLC (Oncovir, Washington, DC) $50 \mu \mathrm{g}$, and when indicated-25 $\mu \mathrm{g}$ of agonist $\alpha$-CD40 mAb. ${ }^{35}$ Unless otherwise specified, vaccines were delivered in a prime-boost fashion with the booster given 4 weeks after priming. Mice were killed 7 weeks after the booster dose. For determining long-term immune responses, mice were killed 25 weeks post boost.

Isolation of mononuclear cells from various organs and cell preparation. Mice were killed and the mononuclear cells were isolated from the following organs:

Intestinal mononuclear cell isolation. As previously described, ${ }^{77}$ small and large intestines were removed in toto and placed in cold HBSS media containing 5\% FCS. The intestines were carefully cleaned from the mesentery and flushed of fecal content. Peyer's patches were removed and analyzed separately where indicated. Intestines were 
opened longitudinally and then cut into $1 \mathrm{~cm}$ pieces. The intestinal tissue was incubated with $1.3 \mathrm{~mm}$ EDTA (Cellgro, Manassas, VA) in HBSS at $37^{\circ} \mathrm{C}$ for $20 \mathrm{~min}$. The EDTA incubation step was repeated a second time. The supernatants containing intestinal epithelial cell with some superficial villi cells, referred to as the "intestinal epithelial cell fraction", were not used in the present study. To isolate the lamina propria lymphocytes, the remaining intestinal tissue was minced and transferred to conical tubes. The minced pieces were resuspended in $20 \mathrm{ml}$ of complete RPMI containing $0.125 \mathrm{mg} \mathrm{ml}^{-1}$ of collagenase (Sigma, St Louis, MO) and shaken at 200 r.p.m. for $50 \mathrm{~min}$ at $37^{\circ} \mathrm{C}$. The tissue suspension was collected and passed through a $70-\mu \mathrm{m}$ cell strainer and the cells were pelleted by centrifugation at 1,600 r.p.m. The cells were then resuspended and layered onto a 20/80\% Percoll (GE Biochemicals, Pittsburgh, PA) gradient, centrifuged and collected, washed and resuspended in complete RPMI media. These purified cells constituted the SILP or colonic lamina propria (CLP) lymphocyte population.

Lung mononuclear cell isolation. The pulmonary circulation was perfused with saline to remove the intravascular pool of cells. Lungs were carefully separated from thymic and cardiovascular remnants and removed in toto. Organs were thoroughly minced using iridectomy scissors and incubated for $60 \mathrm{~min}$ in digestion medium containing 0 . Collagenase $\left(5 \mathrm{mg} / \mathrm{ml}\right.$; Sigma) in a humidified incubator at $37^{\circ} \mathrm{C}$ and $5 \%$ $\mathrm{CO}_{2}$. In the last $5 \mathrm{~min}, 10 \mathrm{~mm}$ EDTA was added. Tissue fragments were disrupted mechanically by pipetting and passed through a $70-\mu \mathrm{m}$ cell strainer and mononuclear cells were washed twice in RPMI. The cells were then layered onto a 20/80 \% Percoll gradient, centrifuged and collected, washed and resuspended in complete RPMI media.

Spleen and LN cell isolation. The spleen and LN were harvested in RPMI media with $5 \% \mathrm{FCS}$ and digested at $37^{\circ} \mathrm{C}$ in the presence of 400 units per $\mathrm{ml}$ of collagenase D (Sigma-Aldrich) or $25 \mathrm{~min}$. In the last $5 \mathrm{~min}, 10 \mathrm{mM}$ EDTA was added. Spleen but not LN samples went through subsequent ACK lysis (Gibco, Waltham, MA), were washed twice and counted.

Vaginal mononuclear cell isolation. The vaginal tract was excised, cut into fine pieces and incubated in collagenase (Sigma) at $0.5 \mathrm{mg} \mathrm{ml}^{-1}$ at $37^{\circ} \mathrm{C}$ for $1 \mathrm{~h}$. Tissue was then homogenized, filtered, and washed. The resulting cell suspension was layered on a $20 / 80 \%$ Percoll gradient and the interface was collected to obtain an enriched mononuclear cell population.

Peripheral blood mononuclear cell isolation. Blood was obtained from the experimental mice by cardiac puncture in heparinized syringes. Mononuclear cells were obtained by layering on Histopaque (Sigma).

Nasal mononuclear cell isolation. Nose-associated lymphoid tissue was isolated as described previously. ${ }^{78}$ Briefly, the entire nose was dissected out, mechanically disrupted using blunt scissors and transferred to conical tubes. The tissue fragments were digested in $10 \mathrm{ml}$ of RPMI containing $0.3 \mathrm{mg} \mathrm{ml}^{-1}$ of collagenase (Sigma-Aldrich) and agitated at 200 r.p.m. for $60 \mathrm{~min}$ at $37^{\circ} \mathrm{C}$. The tissue suspension was collected and passed through a $70-\mu \mathrm{m}$ cell strainer and the cells were pelleted by centrifugation at 1,600 r.p.m. for $5 \mathrm{~min}$. The resulting cell suspension was layered on a $20 / 80 \%$ Percoll gradient and the interface was collected to obtain an enriched mononuclear cell population.

Recall responses to gag-p24 peptides. As described previously, ${ }^{79}$ $2-5 \times 10^{5}$ mononuclear cells isolated from various organs were incubated for $6 \mathrm{~h}$ at $37^{\circ} \mathrm{C}$ with pooled p17 or p24 peptides at a final concentration of $1 \mu \mathrm{g} \mathrm{ml}^{-1}$ in the presence of $\alpha$-CD28 antibody (clone 37.51; American Type Culture Collection), final concentration of $2 \mu \mathrm{g} \mu \mathrm{g} \mathrm{ml}^{-1}$. Notably, as our lab has previously demonstrated that the $\mathrm{CD} 4{ }^{+} \mathrm{T}$-cell response was noted to 24 peptides in pools 1 and 3 and the CD8 ${ }^{+}$T-cell response was directed to 24 peptides in pool 2 (which contained a previously defined gag $197-205$ peptide sequence presented on $\left.\mathrm{H}-2 \mathrm{~K}^{\mathrm{d}}\right),{ }^{19}$ in the present study, mononuclear cells were incubated with the entire reactive HIV gag-p24 or nonreactive HIV gag p17 15-mer peptide mix. After $1 \mathrm{~h}$ of incubation, Brefeldin A (Sigma-Aldrich) was added to a final concentration of $10 \mu \mathrm{g} \mathrm{ml}^{-1} \mathrm{ml}$ for the five remaining hours to allow intracellular cytokine accumulation. For all subsequent steps cells were washed and stained in ice cold PBS with 2\% FCS.

Surface staining and intracellular cytokine staining. Cells were incubated with $\alpha$-mouse-CD3, CD4, or CD8 mAbs (all purchased from BD PharMingen) and Aqua LIVE/DEAD fixable (Invitrogen, Waltham, MA) for $20 \mathrm{~min}$ at $4{ }^{\circ} \mathrm{C}$ after blocking $\mathrm{Fc} \gamma$ receptor with $\alpha$-CD16/CD23 antibody (Bioscience, San Diego, CA). Following fixation with Cytofix/Cytoperm Plus (BD PharMingen, San Jose, CA), cells were stained for intracellular IFN- $\gamma$ (BD Pharmingen) for $30 \mathrm{~min}$ at $4{ }^{\circ} \mathrm{C}$. Data were collected using BD LSR II and analyzed by FlowJo (Tree Star, Ashland, OR). Dead cell were excluded from the analyses, $\mathrm{CD} 3$-gated live $\mathrm{CD} 4{ }^{+} \mathrm{T}$ cells and $\mathrm{CD} 8{ }^{+} \mathrm{T}$ cells were analyzed for the expression of IFN- $\gamma$ as indicated in individual experiments.

Stool and serum gag-specific IgG and IgA. Stool was collected from vaccinated and control mice and suspended in $1 \mathrm{ml}$ of PBS containing protease inhibitor (Roche, Indianapolis, IN). Serum was prepared by cardiac bleed, followed by serum separation using microtainer tubes (BD Biosciences). Stool and serum gag-specific ELISA was performed by coating NUNC plates (Apogent Technologies, Portsmouth, NH) with $2 \mu \mathrm{g} \mu \mathrm{g} \mathrm{ml}^{-1}$ of gag-p24 recombinant protein in ELISA coating buffer overnight at $4{ }^{\circ} \mathrm{C}$. Plates were washed three times with PBS and blocked with blocking solution $(1 \times \mathrm{PBS}, 5 \%$ goat serum, and $0.1 \%$ Tween-20) for $1 \mathrm{~h}$ at $37^{\circ} \mathrm{C}$, followed by sample addition at serial 10 -fold titration (dilutions made into blocking solution) for $2 \mathrm{~h}$ at room temperature, followed by three subsequent washes. A 1:10,000 dilution of goat anti-mouse IgG HRP (Jackson ImmunoResearch) or goat anti-mouse IgA HRP (Life Technologies, Waltham, MA) was added according to standard protocols for $1 \mathrm{~h}$ at $37^{\circ} \mathrm{C}$, the plate was washed three times before addition of $100 \mu \mathrm{l} 1 \mathrm{X}$ TMB Substrate Solution (eBioscience) stopped with addition of $2 \mathrm{~N}$ sulfuric acid, and read at $450 / 470 \mathrm{~nm}$.

Multiplexed ELISA for polyfunctional T cells. One-week post boost, the vaccinated mice were killed and mononuclear cells were isolated from the local (Med LN), systemic (spleen), and GI mucosal (SILP) compartments and re-stimulated with either $\mathrm{p} 24$ or $\mathrm{p} 17$ peptide pools and $\alpha$-CD28 $\left(1 \mu \mathrm{g} \mathrm{ml}^{-1}\right)$ for $20 \mathrm{~h}$. The supernatant was collected and analyzed using a Bio-Plex Pro Mouse Cytokine 23-plex assay (Biorad, Hercules, CA). Briefly, the Bio-Plex assay is an immunoassay, based on magnetic beads, consisting of a sandwich ELISA. Capture antibodies directed against the desired biomarkers were covalently coupled to beads. Coupled beads $(50 \mu \mathrm{l})$ were added to the supernatant $(50 \mu \mathrm{l})$ and incubated for $1 \mathrm{~h}$ at room temperature. After a series of washes to remove unbound protein, a biotinylated detection antibody $(25 \mu \mathrm{l})$ was added and incubated at room temperature for $30 \mathrm{~min}$. The final detection complex was formed with the addition of a streptavidinphycoerthrin conjugate. The samples were resuspended in assay buffer at a volume of $125 \mu \mathrm{l}$. Phycoerytherin served as a fluorescent reporter. The fluorescence was measured in a Luminex-based reader (Biorad). The data were analyzed using Bio-Plex data Pro software.

ELISPOT. Plates were coated with $5 \mu \mathrm{g} \mathrm{ml}^{-1}$ gag-p24 protein overnight. Following washing, plates were blocked with RPMI media containing 10\% FBS (Gibco), 1\% non-essential amino acids (Gibco), $1 \%$ anti-anti cocktail (Gibco), and $0.1 \%$ 2- mercaptoethanol (Gibco). Cells were plated in a concentration of $1-2 \times 10^{6}$ cells per well (GI) in triplicate and cultured for $24 \mathrm{~h}$ at $37^{\circ} \mathrm{C}$, washed, and isotype-specific antibody was detected using HRP-conjugated goat anti-mouse IgA secondary (Southern Biotech). Spots were developed using BD ELISPOT AEC substrate set (551951) according to manufacturers protocol. Spots were quantified using a CTL-ImmunoSpot Analyzer and Software (Shaker Heights, $\mathrm{OH}$ ). 
Statistical analysis. Data reported in the figures represent the average of at least three independent experiments. Error bars represent the s.d. Statistical analysis using the unpaired $t$-test between three groups was done using Prism software (La Jolla, CA).

SUPPLEMENTARY MATERIAL is linked to the online version of the paper at http://www.nature.com/mi

\section{ACKNOWLEDGMENTS}

We would like to acknowledge two dear colleagues in this paper. First and foremost, this work was inspired by late Ralph Steinman. The work was initiated and developed in his laboratory. Second, this project was closely done with the help of late Yoonkyung Do. In addition, we would like to thank Chae Gyu Park for help with the reagents. This work was supported by grants from the American Gastroenterology Association Elsevier Award (S.M.), The Rockefeller University Clinical and Translation science award pilot project from NIH/NCRR (5UL1RR024143-05) National Institutes of Health (S.M.), and The Leona M. and Harry B. Helmsley Charitable Trust, (S.M).

\section{DISCLOSURE}

The authors declared no conflict of interest.

(c) 2016 Society for Mucosal Immunology

\section{REFERENCES}

1. Mehandru, S. et al. Primary HIV-1 infection is associated with preferential depletion of CD4 + Tlymphocytes from effector sites in the gastrointestinal tract. J. Exp. Med. 200 (6), 761-770 (2004).

2. Guadalupe, M. et al. Severe CD4 + T-cell depletion in gut lymphoid tissue during primary human immunodeficiency virus type 1 infection and substantial delay in restoration following highly active antiretroviral therapy. J. Virol. 77 (21), 11708-11717 (2003).

3. Brenchley, J.M. et al. CD4 + Tcell depletion during all stages of HIV disease occurs predominantly in the gastrointestinal tract. J. Exp. Med. 200 (6), 749-759 (2004).

4. Whitney, J.B. et al. Rapid seeding of the viral reservoir prior to SIV viraemia in rhesus monkeys. Nature 512 (7512), 74-77 (2014).

5. Neutra, M.R. \& Kozlowski, P.A. Mucosal vaccines: the promise and the challenge. Nat. Rev. Immunol. 6 (2), 148-158 (2006).

6. Kastenmuller, W., Kastenmuller, K., Kurts, C. \& Seder, R.A. Dendritic celltargeted vaccines - hope or hype? Nat. Rev. Immunol 14 (10), 705-711 (2014).

7. Thakur, A., Pedersen, L.E. \& Jungersen, G. Immune markers and correlates of protection for vaccine induced immune responses. Vaccine 30 (33), 4907-4920 (2012).

8. Carayanniotis, G. \& Barber, B.H. Adjuvant-free IgG responses induced with antigen coupled to antibodies against class II MHC. Nature 327 (6117), 59-61 (1987).

9. Palumbo, R.N., Nagarajan, L. \& Wang, C. Recombinant monomeric CD40 ligand for delivering polymer particles to dendritic cells. Biotechnol. Prog. 27 (3), 830-837 (2011).

10. Mascarell, L. et al. Delivery of the HIV-1 Tat protein to dendritic cells by the CyaA vector induces specific Th1 responses and high affinity neutralizing antibodies in non human primates. Vaccine 24 (17), 3490-3499 (2006).

11. Castro, F.V. et al. CD11c provides an effective immunotarget for the generation of both CD4 and CD8 T cell responses. Eur. J. Immunol. 38 (8), 2263-2273 (2008).

12. Bonifaz, L.C. et al. In vivo targeting of antigens to maturing dendritic cells via the DEC-205 receptor improves T cell vaccination. J. Exp. Med. 199 (6), 815-824 (2004).

13. Idoyaga, J. et al. Cutting edge: langerin/CD207 receptor on dendritic cells mediates efficient antigen presentation on $\mathrm{MHC}$ I and II products in vivo. J. Immunol. 180 (6), 3647-3650 (2008).

14. Apostolopoulos, V., Barnes, N., Pietersz, G.A. \& McKenzie, I.F. Ex vivo targeting of the macrophage mannose receptor generates anti-tumor CTL responses. Vaccine 18 (27), 3174-3184 (2000).
15. Idoyaga, J. et al. Comparable Thelper 1 (Th1) and CD8 T-cell immunity by targeting HIV gag p24 to CD8 dendritic cells within antibodies to Langerin, DEC205, and Clec9A. Proc. Natl Acad. Sci. USA 108 (6), 2384-2389 (2011).

16. Klechevsky, E. et al. Cross-priming CD8 + T cells by targeting antigens to human dendritic cells through DCIR. Blood 116 (10), 1685-1697 (2010).

17. Tacken, P.J. et al. Effective induction of naive and recall T-cell responses by targeting antigen to human dendritic cells via a humanized anti-DC-SIGN antibody. Blood 106 (4), 1278-1285 (2005).

18. Carter, R.W., Thompson, C., Reid, D.M., Wong, S.Y. \& Tough, D.F. Preferential induction of CD4 + Tcell responses through in vivo targeting of antigen to dendritic cell-associated C-type lectin-1. J. Immunol. 177 (4), 2276-2284 (2006).

19. Trumpfheller, C. et al. Intensified and protective CD4 + T cell immunity in mice with anti-dendritic cell HIV gag fusion antibody vaccine. J. Exp. Med. 203 (3), 607-617 (2006).

20. Flynn, B.J. et al. Immunization with HIV Gag targeted to dendritic cells followed by recombinant New York vaccinia virus induces robust T-cell immunity in nonhuman primates. Proc. Natl Acad. Sci. USA 108 (17), 7131-7136 (2011).

21. Bozzacco, L. et al. DEC-205 receptor on dendritic cells mediates presentation of HIV gag protein to CD8 + T cells in a spectrum of human MHC I haplotypes. Proc. Natl Acad. Sci. USA 104 (4), 1289-1294 (2007).

22. Stahl-Hennig, C. et al. Synthetic double-stranded RNAs are adjuvants for the induction of $\mathrm{T}$ helper 1 and humoral immune responses to human papillomavirus in rhesus macaques. PLoS Pathog. 5 (4), e1000373 (2009).

23. Yanagita, M. et al. Nasopharyngeal-associated lymphoreticular tissue (NALT) immunity: fimbriae-specific Th1 and Th2 cell-regulated IgA responses for the inhibition of bacterial attachment to epithelial cells and subsequent inflammatory cytokine production. J. Immunol. 162 (6), 3559-3565 (1999).

24. Sandoval, F. et al. Mucosal imprinting of vaccine-induced CD8 $(+)$ Tcells is crucial to inhibit the growth of mucosal tumors. Sci. Transl. Med. 5 (172), 172ra20 (2013).

25. Langermann, S., Palaszynski, S., Sadziene, A., Stover, C.K. \& Koenig, S. Systemic and mucosal immunity induced by BCG vector expressing outersurface protein A of Borrelia burgdorferi. Nature 372 (6506), 552-555 (1994).

26. Velge-Roussel, F., Marcelo, P., Lepage, A.C., Buzoni-Gatel, D. \& Bout, D.T. Intranasal immunization with Toxoplasma gondii SAG1 induces protective cells into both NALT and GALT compartments. Infect. Immun. 68 (2), 969-972 (2000).

27. Hawiger, D. et al. Dendritic cells induce peripheral T cell unresponsiveness under steady state conditions in vivo. J. Exp. Med. 194 (6), 769-779 (2001).

28. Belyakov, I.M., Isakov, D., Zhu, Q., Dzutsev, A. \& Berzofsky, J.A. A novel functional CTL avidity/activity compartmentalization to the site of mucosal immunization contributes to protection of macaques against simian/ human immunodeficiency viral depletion of mucosal CD4 $+\mathrm{T}$ cells. $\mathrm{J}$ Immunol. 178 (11), 7211-7221 (2007).

29. Ruane, D. et al. Lung dendritic cells induce migration of protective Tcells to the gastrointestinal tract. J. Exp. Med. 210 (9), 1871-1888 (2013).

30. Do, Y. et al. Induction of pulmonary mucosal immune responses with a protein vaccine targeted to the DEC-205/CD205 receptor. Vaccine 30 (45), 6359-6367 (2012)

31. Meredith, M.M. et al. Expression of the zinc finger transcription factor zDC (Zbtb46, Btbd4) defines the classical dendritic cell lineage. J. Exp. Med. 209 (6), 1153-1165 (2012).

32. Douek, D.C. et al. HIV preferentially infects HIV-specific CD4 + T cells. Nature 417 (6884), 95-98 (2002).

33. Harari, A. et al. An HIV-1 clade C DNA prime, NYVAC boost vaccine regimen induces reliable, polyfunctional, and long-lasting Tcell responses. J. Exp. Med. 205 (1), 63-77 (2008).

34. Mata, M., Travers, P.J., Liu, Q., Frankel, F.R. \& Paterson, Y. The MHC class I-restricted immune response to HIV-gag in BALB/c mice selects a single epitope that does not have a predictable MHC-binding motif and binds to Kd through interactions between a glutamine at $\mathrm{P} 3$ and pocket $\mathrm{D}$. J Immunol 161 (6), 2985-2993 (1998).

35. Ahonen, C.L. et al. Combined TLR and CD40 triggering induces potent CD8 + T cell expansion with variable dependence on type I IFN. J. Exp. Med. 199 (6), 775-784 (2004). 
36. Centers for Disease Control (CDC). Pneumocystis pneumonia-Los Angeles. MMWR Morbidity and mortality weekly report 30 (21), 250-252 (1981).

37. Crunkhorn, S. Infectious disease: Towards an effective HIV vaccine. Nature reviews Drug discovery 14 (4), 238 (2015).

38. Nchinda, G., Amadu, D., Trumpfheller, C., Mizenina, O., Uberla, K. \& Steinman, R.M. Dendritic cell targeted HIV gag protein vaccine provides help to a DNA vaccine including mobilization of protective CD8 + T cells. Proc. Natl Acad. Sci. USA 107 (9), 4281-4286 (2010).

39. Cheong, C. et al. Improved cellular and humoral immune responses in vivo following targeting of HIV Gag to dendritic cells within human anti-human DEC205 monoclonal antibody. Blood 116 (19), 3828-3838 (2010).

40. Belyakov, I.M. \& Ahlers, J.D. Functional CD8 + CTLs in mucosal sites and HIV infection: moving forward toward a mucosal AIDS vaccine. Trends Immunol. 29 (11), 574-585 (2008).

41. Belyakov, I.M., Ahlers, J.D., Nabel, G.J., Moss, B. \& Berzofsky, J.A. Generation of functionally active HIV-1 specific CD8 + CTL in intestinal mucosa following mucosal, systemic or mixed prime-boost immunization. Virology 381 (1), 106-115 (2008).

42. Gallichan, W.S. \& Rosenthal, K.L. Long-lived cytotoxic T lymphocyte memory in mucosal tissues after mucosal but not systemic immunization. J. Exp. Med. 184 (5), 1879-1890 (1996).

43. Rerks-Ngarm, S. et al. Vaccination with ALVAC and AIDSVAX to prevent HIV-1 infection in Thailand. N. Engl. J. Med. 361 (23), 2209-2220 (2009).

44. McElrath, M.J. et al. HIV-1 vaccine-induced immunity in the test-ofconcept step study: a case-cohort analysis. Lancet 372 (9653), 18941905 (2008).

45. Buchbinder, S.P. et al. Efficacy assessment of a cell-mediated immunity HIV-1 vaccine (the step study): a double-blind, randomised, placebocontrolled, test-of-concept trial. Lancet 372 (9653), 1881-1893 (2008).

46. Gray, G., Buchbinder, S. \& Duerr, A. Overview of STEP and Phambili trial results: two phase llb test-of-concept studies investigating the efficacy of MRK adenovirus type $5 \mathrm{gag} / \mathrm{pol} / \mathrm{nef}$ subtype B HIV vaccine. Curr. Opin. HIV AIDS 5 (5), 357-361 (2010).

47. Hutnick, N.A. et al. Baseline Ad5 serostatus does not predict Ad5 HIV vaccine-induced expansion of adenovirus-specific CD4 + T cells. Nat. Med. 15 (8), 876-878 (2009).

48. O'Brien, K.L. et al. Adenovirus-specific immunity after immunization with an Ad5 HIV-1 vaccine candidate in humans. Nat. Med. 15 (8), 873-875 (2009).

49. Masek-Hammerman, K. et al. Mucosal trafficking of vector-specific CD4 + $T$ lymphocytes following vaccination of rhesus monkeys with adenovirus serotype 5. J. Virol. 84 (19), 9810-9816 (2010).

50. Williams, W.B. et al. HIV-1 VACCINES. Diversion of HIV-1 vaccine-induced immunity by gp41-microbiota cross-reactive antibodies. Science $\mathbf{3 4 9}$, aab1253 (2015).

51. Haynes, B.F. et al. Immune-correlates analysis of an HIV-1 vaccine efficacy trial. N. Engl. J. Med. 366 (14), 1275-1286 (2012).

52. de Souza, M.S. et al. The Thai phase III trial (RV144) vaccine regimen induces $\mathrm{T}$ cell responses that preferentially target epitopes within the V2 region of HIV-1 envelope. J Immunol. 188 (10), 5166-5176 (2012).

53. Kuebler, P.J. et al. Cellular immune correlates analysis of an HIV-1 preexposure prophylaxis trial. Proc. Natl Acad. Sci. USA 112 (27), 8379-8384 (2015).

54. Bart, P.A. et al. HIV-specific humoral responses benefit from stronger prime in phase Ib clinical trial. J. Clin. Invest. 124 (11), 4843-4856 (2014).

55. Bienenstock, J., McDermott, M., Befus, D. \& O'Neill, M. A common mucosal immunologic system involving the bronchus, breast and bowel. Adv. Exp. Med. Biol. 107, 53-59 (1978).

56. Stary, G. et al. VACCINES. A mucosal vaccine against Chlamydia trachomatis generates two waves of protective memory T cells. Science 348, aaa8205 (2015).

57. Harandi, A.M. \& Medaglini, D. Mucosal adjuvants. Curr. HIV Res. 8 (4), 330-335 (2010).

58. Krown, S.E., Kerr, D., Stewart, W.E. 2nd, Field, A.K. \& Oettgen, H.F. Phase I trials of poly(l,C) complexes in advanced cancer. J. Biol. Response Mod. 4 (6), 640-649 (1985).
59. Morse, M.A. et al. Phase I study utilizing a novel antigen-presenting celltargeted vaccine with Toll-like receptor stimulation to induce immunity to self-antigens in cancer patients. Clin. Cancer Res. 17 (14), 4844-4853 (2011).

60. Okada, H. et al. Induction of CD8 + T-cell responses against novel gliomaassociated antigen peptides and clinical activity by vaccinations with \{alpha\}-type 1 polarized dendritic cells and polyinosinic-polycytidylic acid stabilized by lysine and carboxymethylcellulose in patients with recurrent malignant glioma. J. Clin. Oncol. 29 (3), 330-336 (2011).

61. Caskey, M. et al. Synthetic double-stranded RNA induces innate immune responses similar to a live viral vaccine in humans. J. Exp. Med. 208 (12), 2357-2366 (2011).

62. Witmer-Pack, M.D., Swiggard, W.J., Mirza, A., Inaba, K. \& Steinman, R.M. Tissue distribution of the DEC-205 protein that is detected by the monoclonal antibody NLDC-145. II. Cell Immunol. 163 (1), 157-162 (1995).

63. Graw, F. \& Regoes, R.R. Predicting the impact of CD8 $+\mathrm{T}$ cell polyfunctionality on HIV disease progression. J. Virol. 88 (17), 1013410145 (2014).

64. Cocchi, F. et al. Higher macrophage inflammatory protein (MIP)-1alpha and MIP-1beta levels from CD8 + T cells are associated with asymptomatic HIV-1 infection. Proc. Natl Acad. Sci. USA 97 (25), 13812-13817 (2000).

65. Khader, S.A. et al. IL-23 and IL-17 in the establishment of protective pulmonary $\mathrm{CD} 4+\mathrm{T}$ cell responses after vaccination and during Mycobacterium tuberculosis challenge. Nat. Immunol. 8 (4), 369-377 (2007).

66. Smiley, K.L., McNeal, M.M., Basu, M., Choi, A.H., Clements, J.D. \& Ward, R.L. Association of gamma interferon and interleukin-17 production in intestinal CD4 + Tcells with protection against rotavirus shedding in mice intranasally immunized with VP6 and the adjuvant LT(R192G). J. Virol. 81 (8), 3740-3748 (2007).

67. Cecchinato, V. et al. Altered balance between Th17 and Th1 cells at mucosal sites predicts AIDS progression in simian immunodeficiency virusinfected macaques. Mucosal Immunol 1 (4), 279-288 (2008).

68. Xu, H., Wang, X., Liu, D.X., Moroney-Rasmussen, T., Lackner, A.A. \& Veazey, R.S. IL-17-producing innate lymphoid cells are restricted to mucosal tissues and are depleted in SIV-infected macaques. Mucosal Immunol 5 (6), 658-669 (2012).

69. Horwitz, J.A. et al. HIV-1 suppression and durable control by combining single broadly neutralizing antibodies and antiretroviral drugs in humanized mice. Proc. Natl Acad. Sci. USA 110 (41), 16538-16543 (2013).

70. Klein, F. et al. HIV therapy by a combination of broadly neutralizing antibodies in humanized mice. Nature 492 (7427), 118-122 (2012).

71. Barouch, D.H. et al. Therapeutic efficacy of potent neutralizing HIV-1-specific monoclonal antibodies in SHIV-infected rhesus monkeys. Nature 503 (7475), 224-228 (2013).

72. Halper-Stromberg, A. et al. Broadly neutralizing antibodies and viral inducers decrease rebound from HIV-1 latent reservoirs in humanized mice. Cell 158 (5), 989-999 (2014).

73. Rolland, M. et al. Increased HIV-1 vaccine efficacy against viruses with genetic signatures in Env V2. Nature 490 (7420), 417-420 (2012).

74. Boscardin, S.B. et al. Antigen targeting to dendritic cells elicits long-lived T cell help for antibody responses. J. Exp. Med. 203 (3), 599-606 (2006).

75. Gomez, C.E. et al. Generation and immunogenicity of novel HIV/AIDS vaccine candidates targeting HIV-1 Env/Gag-Pol-Nef antigens of clade C. Vaccine 25 (11), 1969-1992 (2007).

76. Bozzacco, L. et al. HIV gag protein is efficiently cross-presented when targeted with an antibody towards the DEC-205 receptor in Flt3 ligandmobilized murine DC. Eur. J. Immunol. 40 (1), 36-46 (2010).

77. Mucida, D. et al. Reciprocal TH17 and regulatory T cell differentiation mediated by retinoic acid. Science 317 (5835), 256-260 (2007).

78. Lee, $\mathrm{H}$. et al. Phenotype and function of nasal dendritic cells. Mucosal Immunol. 8 (5), 1083-1098 (2015).

79. Trumpfheller, C. et al. The microbial mimic poly IC induces durable and protective CD4 $+\mathrm{T}$ cell immunity together with a dendritic cell targeted vaccine. Proc. Natl Acad. Sci. USA 105 (7), 2574-2579 (2008). 